\section{Suggested Actions}

- Use PHAST with current and projected energy costs to estimate energy savings from waste heat recovery.

- Contact furnace or combustion system suppliers to calculate payback or return on investment.

\section{Resources}

U.S. Department of EnergyFor additional information on process heating system efficiency, to obtain DOE's publications and Process Heating Assessment and Survey Tool (PHAST) software, or learn more about training, visit the BestPractices Web site at www.eere.energy.gov/industry/ bestpractices.

\title{
Install Waste Heat Recovery Systems for Fuel-Fired Furnaces
}

For most fuel-fired heating equipment, a large amount of the heat supplied is wasted as exhaust or flue gases. In furnaces, air and fuel are mixed and burned to generate heat, some of which is transferred to the heating device and its load. When the heat transfer reaches its practical limit, the spent combustion gases are removed from the furnace via a flue or stack. At this point, these gases still hold considerable thermal energy. In many systems, this is the

\section{Figure 1. Heat in flue gas}

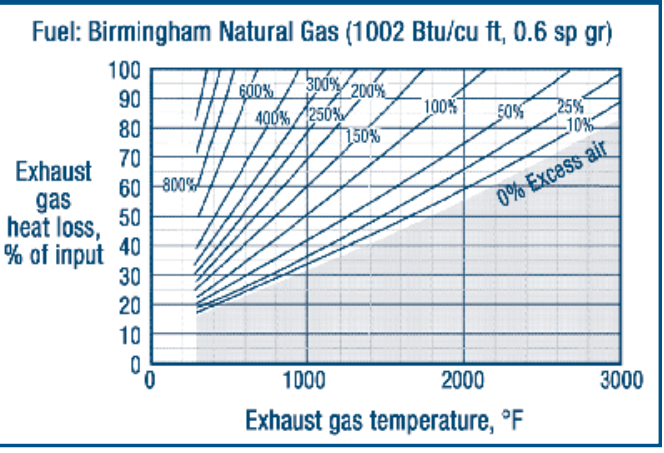
greatest single heat loss. The energy efficiency can often be increased by using waste heat gas recovery systems to capture and use some of the energy in the flue gas.

For natural gas-based systems, the amount of heat contained in the flue gases as a percentage of the heat input in a heating system can be estimated by using Figure 1 . Exhaust gas loss or waste heat depends on flue gas temperature and its mass flow, or in practical terms, excess air resulting from combustion air supply and air leakage into the furnace. The excess air can be estimated by measuring oxygen percentage in the flue gases.

\section{Waste Heat Recovery}

Heat losses must be minimized before waste heat recovery is investigated. Figure 2 highlights opportunities for energy savings.

The most commonly used waste heat recovery methods are preheating combustion air, steam generation and water heating, and load preheating.

\section{Preheating}

Combustion Air.

A recuperator is the most widely used heat recovery device. It is a gas-to-gas heat exchanger placed on the stack of the furnace that preheats incoming air with exhaust gas. Designs rely on tubes or plates to transfer heat from the exhaust gas to the combustion air and keep the streams from mixing.

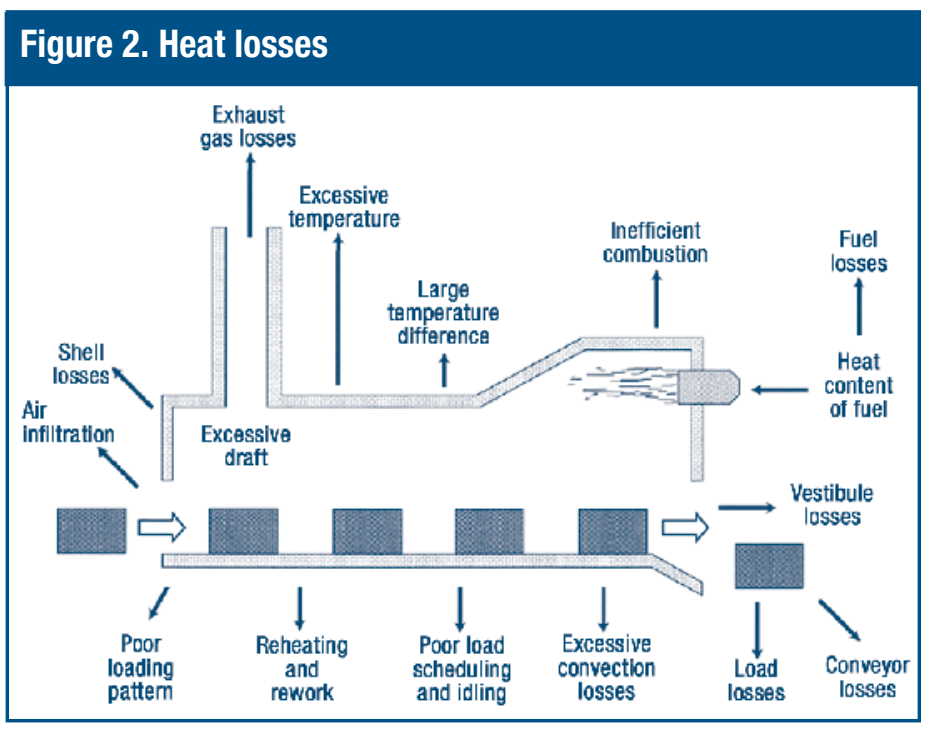


Another way to preheat combustion air is with a regenerator, which is an insulated container filled with metal or ceramic shapes that can absorb and store significant thermal energy. It acts as a rechargeable storage battery for heat. Incoming cold combustion air is passed through the regenerator. At least two regenerators and their associated burners are required for an uninterrupted process: one provides energy to the combustion air while the other recharges.

Steam Generation and Water Heating. These systems are similar to conventional boilers but are larger because the exhaust gas temperature is lower than the flame temperature used in conventional systems. Waste heat boilers can be used on most furnace applications, and special designs and materials are available for systems with corrosive waste gases. Plants that need a source of steam or hot water can use waste heat boilers, which may also work for plants that want to add steam capacity. However, the waste boiler generates steam only when the fuel-fired process is operating.

Load Preheating. If exhaust gases leaving the high temperature portion of the process can be brought into contact with a relatively cool incoming load (the material being heated), energy will be transferred to the load, preheating it and reducing the energy consumption. Load preheating has the highest potential efficiency of any system that uses waste gases. Load preheating systems can be difficult to retrofit and are best suited for continuous rather than batch furnaces.

\section{Benefits}

Benefits of waste heat recovery include:

- Improved heating system efficiency. Energy consumption can typically be reduced $5 \%$ to $30 \%$

- Lower flue gas temperature in chimney. Less heat is wasted.

- Higher flame temperatures. Combustion air preheating heats furnaces better and faster.

- Faster furnace startup. Combustion air preheating heats furnaces faster.

- Increased productivity. Waste heat used for load preheating can increase throughput.

\section{Potential Applications}

Waste heat recovery should generally be considered if the exhaust temperature is higher than $1,000^{\circ} \mathrm{F}$, or if the flue gas mass flow is very large.

\section{References}

Improving Process Heating System Performance: A Sourcebook for Industry. U.S. Department of Energy (DOE) and the Industrial Heating Equipment Association (IHEA). This document can be obtained from www.oit.doe.gov/ bestpractices/library.shtml.

Waste Heat Reduction and Recovery for Improving Furnace Efficiency. DOE and IHEA. This document can be obtained from www.oit.doe.gov/ bestpractices/library.shtml.
BestPractices is part of the Industrial Technologies Program Industries of the Future strategy, which helps the country's most energy-intensive industries improve their competitiveness. BestPractices brings together emerging technologies and best energy-management practices to help companies begin improving energy efficiency, environmental performance, and productivity right now.

BestPractices emphasizes plant systems, where significant efficiency improvements and savings can be achieved. Industry gains easy access to near-term and long-term solutions for improving the performance of motor, steam, compressed air, and process heating systems. In addition, the Industrial Assessment Centers provide comprehensive industrial energy evaluations to small- and medium-size manufacturers.

FOR ADDITIONAL INFORMATION, PLEASE CONTACT:

EERE Information Center

1-877-EERE-INF

(1-877-337-3463)

www.eere.energy.gov

Industrial Technologies Program Energy Efficiency and Renewable Energy U.S. Department of Energy Washington, DC 20585-0121 www.eere.energy.gov/industry

\section{A Strong Energy Portfolio for a Strong America}

Energy efficiency and clean, renewable energy will mean a stronger economy, a cleaner environment, and greater energy independence for America. Working with a wide array of state, community, industry, and university partners, the U.S. Department of Energy's Office of Energy Efficiency and Renewable Energy invests in a diverse portfolio of energy technologies. 